\title{
Oral health treatment needs of HIV/AIDS patients in Ife-Ijesa zone, Nigeria \\ Adedigba M.A ${ }^{1}$ Ogunbodede E.O ${ }^{1}$, Jeboda S.O $^{2}$ and Naidoo $S^{3}$ \\ ${ }^{1}$ Department of Preventive and Community Dentistry, Obafemi Awolowo University, Ile-Ife. ${ }^{2}$ Department of Preventive Dentistry, LUTH, Lagos. \\ ${ }^{3}$ Department of Community Dentistry, University of Western Cape, Cape Town, RSA.
}

Adedigba M.A Ogunbodede E.O., Jeboda S.O and Naidoo S Oral health treatment needs $\mathrm{f}$ HIV/AIDS patients in IfeIjesa zone, Nigeria. Tanz Dent. J. 2007; 14 (1): 8-14

\begin{abstract}
:
The objective of this study was to determine the oral health status and needs of people living with HIV/AIDS (PLWHA) in Ife-Ijesa zone, Nigeria. Materials and methods: An anonymous, administered questionnaire survey among 209 PLWHA who provided informed, written consent was conducted. Information on socio-demographics, perceived oral health status and professional care obtained. Clinical oral examinations were conducted using a dental explorer and mirror in natural daylight. The oral examinations were carried out to determine, presence of oral HIV lesions, normative needs-oral hygiene and periodontal status, restorative and surgical needs. Results: There was a statistically significant relationship between the presence of an oral HIV lesion and perceived oral health status. Patients that reported the need for oral health care are more than those of medical needs $(\mathrm{p}<0.05)$. The oral health needs increased as the clinical stage of the disease advanced $(\mathrm{p}<0.05)$. There was poor oral health status among the PLWHA and their needs were routine. Conclusions: The oral health status of the examined PLWHAs was poor. The normative and the perceived oral health evaluation were not in agreement in this study. The normative oral health care needs of PLWHAs are not complex and hence district oral health care centres should be equipped to meet these needs.
\end{abstract}

Key words: HIV/AIDS, Oral health, treatment needs.

Correspondents: Dr. Adedigba M.A., Department of Preventive and Community Dentistry, Obafemi Awolowo University, Ile-Ife. e-mail: adedigba@ oauife.edu.ng or ademich2002@yahoo.com, +234-8037149761.

\section{Introduction}

The first case of HIV/AIDS in Nigeria was reported in 1986, 5 years after the first case in the world was diagnosed. Since then, the epidemic has been on the increase with $5.8 \%$ (1) prevalence rate reported in 2002. It has been reported that between $70-90 \%$ of people living with HIV/AIDS (PLWHA) will have at least one oral HIV manifestation at a point during the course of the disease (2). The majority of earlier oral health care reports among the PLWHA focused on the oral manifestations of HIV and did not focus on their oral health needs (3).

In a previous report (4), $75 \%$ of the PLWHA reported one or more oral symptoms, indicating the magnitude of the problem and need for oral health care workers to be able to manage them adequately. It was reported that only $14 \%$ of the PLWHA surveyed were able to obtain satisfactory dental care (5).

The importance of oral health cannot be over emphasized among these patients. The early diagnosis and prompt treatment of infectious oral mucosa lesions commonly associated with HIV/AIDS patients will reduce the burden of the morbidity and spread to multiple organ systems in this group of patients (6). Tukutuku et al., (7) studied a cohort population of HIV/AIDS in Kinshasa, Zaire and found that the oral hygiene of HIV/AIDS patients was good with a low plaque index. However, it was re-iterated that despite the fact that they had good oral hygiene, it did not preclude the occurrence of periodontal diseases, which are often severe (8). Oral hygiene scores as one of the major predictors of oral health status has been reported to best predict dentist/objective overall health status $(9,10)$. Good oral hygiene will in no doubt have a great influence on the outcome of oral health status. Most of oral the diseases (caries, periodontal etc) are directly/indirectly related to poor oral hygiene. High association has been obtained in previous studies $(9,10)$. Good oral health was reported in two-third of PLWHAs from a USA study (11). This was contrary to the findings of another study in a developing country, where $78.9 \%$ needed dental treatment and that their oral health status was poor (12). Oral health has been reported as a major area of need among women living with HIV/AIDS in Brazil (13).

AIDS is associated with weight loss (6) and a risk of dehydration, which can result from poor oral health, impaired mastication and swallowing of fluid, food and medication (14) as well as, associated diarrhoea. Determining the oral health needs of PLWHA will go a long way in planning and achieving total health for HIV infected people. The objective of this study was to determine the oral health status, normative and perceived oral health needs of people living with HIV/AIDS (PLWHA) in Nigeria. 


\section{Materials and methods}

The research design was descriptive and prospective. The study was conducted among 209 people living with HIV/AIDS (PLWHA) attending the general and teaching hospitals over a period of eight months $\left(1^{\text {st }}\right.$ October 2002 to $31^{\text {st }}$ of May 2003) in Ife-Ijesa zone, Nigeria. All consecutive consenting PLWHAs were recruited in to this study. All PLWHA has ELISA and Western blot techniques for the establishment of their diagnosis. Possession of HIV/AIDS confirmation was an inclusive criterion while PLWHA below age of 16years were excluded. A questionnaire was administered to each patient. Information such as socio-demographics and educational status, as well as patients' pattern of oral hygiene and history of professional care were obtained.

All the clinical oral examinations were conducted by one author (A.M.A.). This was done under natural daylight with patient sitting on an ordinary upright chair, using dental explorers and mirrors. The Oral hygiene Index of Greene and Vermillion (15) was used to assess the oral hygiene of the patients. The presence or absence of oral HIV lesions was recorded. The EC Clearinghouse and WHO clinical staging (16) was used to determine the stage of HIV/AIDS infection.

The diagnosis and treatment protocol used in this study was based on the workshop on periodontal diseases in HIV-infected individuals held at the fourth International Workshop on Oral Manifestations of HIV in South Africa, July 2000 (17, 18). Restorative treatment needs were assessed by counting the number of carious teeth requiring fillings, root canal treatment and crowns needed. The prosthetic need was determined based on whether partial/complete dentures are already in use or required. Oral surgical treatment needs was assessed by clinically determining the needs such as routine or surgical extraction(s), management of bone necrosis, alveolar abscess and control of oro-facial infection. Patient's data were recorded with anonymity using only the patient's outpatient card number without their names and addresses written on the questionnaires and on the data capture sheets. Those patients requiring treatment were referred to appropriate units of the dental hospital for management. The data was analysed using SPSS (version 11.0) (19) and EPIINFO (version 6.04) (20). To ascertain the nature of the relationship between the dependent variable (perceived oral health status) and the components of the predictor variables, each of the independent (predictor) variables was considered singly, the data were subjected to separate multiple regression analysis. The model was checked for linearity, normality and influential points and was satisfactory.

\section{Results}

Two hundred and nine PLWHA agreed to participate in the study, $36.4 \%$ were males and $63.6 \%$ females with the mean age of $35.5(+/-10.0)$ years. Ninety two $(44.0 \%)$ had primary education, $34 \%$ secondary, $16.3 \%$ tertiary and the remaining had no formal education.

Table 1 shows the presence of oral HIV lesion(s). Sixty six $(93.0 \%)$ had an oral HIV lesion and they perceived their oral health status as being "poor". Sixty eight percent of those who had no oral lesion perceived their oral health status as "excellent". There was a statistically significant relationship between the presence of oral HIV lesion and the perceived oral health status $(\mathrm{p}<0.05)$.

Table 1: Oral health status and the presence of oral HIV lesions

\begin{tabular}{|c|c|c|c|c|c|c|c|c|c|c|c|c|}
\hline \multirow{3}{*}{$\begin{array}{l}\text { Presence } \\
\text { oral lesion }\end{array}$} & \multicolumn{12}{|c|}{ Perceived Oral Health status } \\
\hline & \multicolumn{2}{|c|}{ Poor } & \multicolumn{2}{|c|}{ Fair } & \multicolumn{2}{|c|}{ Good } & \multicolumn{2}{|c|}{ Very Good } & \multicolumn{2}{|c|}{ Excellent } & \multicolumn{2}{|c|}{ Total } \\
\hline & $\mathrm{n}$ & $\%$ & $\mathrm{n}$ & $\%$ & $\mathrm{n}$ & $\%$ & $\mathrm{n}$ & $\%$ & $\mathrm{n}$ & $\%$ & $\mathrm{n}$ & $\%$ \\
\hline Yes & 66 & 93.0 & 34 & 61.8 & 14 & 50.0 & 9 & 25.7 & 6 & 31.6 & 129 & 62.0 \\
\hline No & 5 & 7.0 & 21 & 38.2 & 14 & 50.0 & 26 & 74.3 & 13 & 68.4 & 79 & 38.0 \\
\hline Total & 71 & 100.0 & 55 & 100.0 & 28 & 100.0 & 35 & 100.0 & 19 & 100.0 & 208 & 100 \\
\hline
\end{tabular}

There were $61.5 \%$ participants who reported that they needed dental care more in the last three months, and $11.5 \%$ felt they needed dental care more than any other health/medical needs (Table 2). There was a statistically significant relationship between those that needed dental care more in the last three months and those that presently needed it more than any other health/medical needs $(\mathrm{p}<0.05)$. 
Table 3 shows that the general health care needs of PLWHA increased as the stage of the disease increased. The health care needs among the Stage IV patients $(86.4 \%)$ were high and this was a statistically significant difference $(\mathrm{p}<0.05)$.

There were $8.1 \%$ patients who had their normative oral hygiene as "very good", $43.5 \%$ as "good", $37.3 \%$ "fair" and $11.0 \%$ "poor". There was a statistically significant relationship between the incidence of acute ulcerative gingivitis (AUG) and $\mathrm{OH}$ status $\left(\chi^{2}=10.03\right.$, df $\left.=2, \mathrm{p}=0.007\right)$.

There was no statistically significant relationship between the perceived oral health status and the actual oral hygiene status $\left(\chi^{2}=8.607, \mathrm{df}=12, \mathrm{p}=0.74\right)$. Out of 72 who perceived to have poor oral health status only $11(15.3 \%)$ had "poor" oral hygiene, whereas 19 rated their oral health status as excellent but only $3(17.6 \%)$ of them were actually so.

Table 2: Dental health care needs

\begin{tabular}{|c|c|c|c|c|c|c|}
\hline \multirow{3}{*}{$\begin{array}{l}\text { Needed dental } \\
\text { care more than } \\
\text { any other needs }\end{array}$} & \multicolumn{6}{|c|}{ Needed dental care more in the last 3 months } \\
\hline & \multicolumn{2}{|c|}{ Yes } & \multicolumn{2}{|c|}{ No } & \multicolumn{2}{|c|}{ Total } \\
\hline & $\mathrm{n}$ & $\%$ & $\mathrm{n}$ & $\%$ & $\mathrm{n}$ & $\%$ \\
\hline Yes & 59 & 61.5 & 13 & 11.5 & 72 & 34.4 \\
\hline No & 37 & 38.5 & 100 & 88.5 & 137 & 65.6 \\
\hline Total & 113 & 100.0 & 96 & 100.0 & 209 & 100.0 \\
\hline
\end{tabular}

Using multiple regression analysis, the relationship between perceived oral health status and the predictor variables, yielded an $\mathrm{R}^{2}$ value of 0.078 , which was significant, $(\mathrm{p}=0.036)$. (Table 4$)$.

Table 5 shows that $12.0 \%$ patients had no general or other health complaints, $23.9 \%$ had oral complaints while more than tow thirds $(64.1 \%)$ had complaints from other parts of the body.

Table 6 shows that professional prophylaxis and oral hygiene instructions (OHI) rank highest (77.5\%) among the periodontal treatment needs of PLWHA. Among the PLWHAs examined, $7.2 \%$ and $1.0 \%$ required routine and surgical extractions respectively. Less than one percent requires management for bone necrosis and dento-alveolar abscess respectively. There were $12.0 \%$ requiring amalgam filling from dental caries, followed by partial dentures $(11.5 \%)$, $1.9 \%$ requires anterior jacket crown and $0.5 \%$ obturator for a palatal defect of a previously done maxillectomy.

Table 3: Perceived general health needs against stage of the disease

\begin{tabular}{lccccccccccc}
\hline General & & \multicolumn{4}{c}{ Stage of the disease } & \multicolumn{3}{c}{ Total } \\
Health needs & \multicolumn{2}{c}{ I } & \multicolumn{2}{c}{ II } & \multicolumn{2}{c}{ III } & \multicolumn{2}{c}{ IV } & & \\
& $\mathrm{n}$ & $\%$ & $\mathrm{n}$ & $\%$ & $\mathrm{n}$ & $\%$ & $\mathrm{n}$ & $\%$ & $\mathrm{n}$ & $\%$ \\
\hline Yes & 11 & 50.0 & 32 & 71.1 & 102 & 85.0 & 19 & 86.4 & 164 & 78.5 \\
No & 11 & 50.0 & 13 & 28.9 & 18 & 15.0 & 3 & 13.6 & 45 & 21 \\
Total & 22 & 100.0 & 45 & 100.0 & 120 & 100.0 & 22 & 100.0 & 209 & 100.0 \\
\hline$\chi^{2}=15.84, \mathrm{df}=3, \mathrm{p}=0.001$ & & & & & & & & & &
\end{tabular}

\section{Discussion}

There were more females $(63.6 \%)$ that participated in this study and this may be due to the health seeking behaviour of women. The level of education among the PLWHA in the present study was low with $16.3 \%$ having tertiary education and few had formal employment (12.0\%). These demographic factors may have affected their oral health status and needs adversely (21).

The perception of oral health status of PLWHA was a reflection of the presence of oral lesions. PLWHA regarded the presence of oral HIV lesion as a state of poor oral health. There has been a close association between poor oral health with weight loss/wasting (6) and a risk of dehydration. This perception (of oral health status) will surely affect the mastication and swallowing of fluid, food and medication (14), which can synergistically affect the patient's weight.

The self-reported care needs of PLWHA in this study reveal that there were many PLWHA who needed dental treatment. Furthermore, the desire for oral health care, above other health care needs shows that the oral health care needs among PLWHA was great and oral health care workers must be prepared to manage these needs. 
Table 4: Summary of multiple regression analysis on relationship between perceived oral health status and possible predictor variables

\begin{tabular}{lcccc}
\hline Model & Beta & $\mathrm{P}$ & \multicolumn{2}{c}{ 95\% Confidence Interval } \\
\cline { 4 - 5 } & & & Lower bound & Upper bound \\
\hline (constant) & - & 0.000 & 2.525 & 3.393 \\
Oral hygiene status & -0.116 & 0.095 & -0.426 & 0.034 \\
Pseudomembranous & & & & \\
Candidiasis & -0.130 & 0.066 & -0.727 & 0.024 \\
Erythematous Candidiasis & -0.076 & 0.279 & -0.633 & 0.183 \\
Hyperplastic Candidiasis & -0.083 & 0.230 & -3.010 & 0.729 \\
Angular Cheilitis & -0.116 & 0.098 & -0.757 & 0.064 \\
Linear gingival erythema & 0.056 & 0.417 & -0.356 & 0.855 \\
Acute ulcerative gingivitis & 0.087 & 0.214 & -0.408 & 1.807 \\
HIV periodontitis & 0.065 & 0.348 & -0.473 & 1.339 \\
\hline & $\mathrm{R}^{2}$ & 0.078 & &
\end{tabular}

Two thirds reported their oral health status as "fair" or "poor" which differs from the findings of Shiboski et al., (4) but similar to that of Pinheiro et al. (12). Eight three per cent reported a specific oral symptom which was higher than $75.0 \%$ obtained in previous work (4). The higher reports of poor oral health state and the report of specific symptoms could be as a result of the lower socio-economic status, poor level of education and poor dental awareness. These factors are known to affect oral health, but do not appear to be as pronounced as in subjects who participated in the USA study (4).

A few of the respondents (11.5\%) were partially edentulous requiring the use of dentures. These figures are lower when compared to the previous study (4). The lower prevalence of tooth loss may be accounted for by many factors such as the pattern of diet, oral hygiene practices and that tooth loss not common among Africans (22). All the respondents who reported tooth loss were not using dentures to replace missing teeth. This could be due to poor oral health awareness and that the enabling factors to receive the care were not there, including the absence of medical insurance. The poor oral health awareness has been reported among the general population in Nigeria (23). This low level of dental awareness may have adverse consequences to PLWHA, in view of the high prevalence of oral HIV lesions $(23,24)$.

The oral hygiene status of the PLWHA in this study was good. This was in agreement with the Tukutuku et al. (7) findings that PLWHA had good oral hygiene with low plaque indices, but other workers $(8,16)$ found that despite the good oral hygiene it did not preclude severe periodontal disease. This is further supported by the statistically significant association between Acute Ulcerative Gingivitis (AUG) and oral hygiene status.
Table 5: Presenting Chief complaints on general and oral health among PLWHA

\begin{tabular}{lcc}
\hline Type of presenting complaints & $\mathbf{n}$ & $\mathbf{\%}$ \\
\hline No complaints & 25 & 12.0 \\
All tongue symptoms & 10 & 4.8 \\
Difficulty in swallowing & 3 & 1.4 \\
Hole in tooth & 1 & 0.5 \\
Sore mouth/ throat & 34 & 16.3 \\
Oral thrush & 2 & 1.0 \\
Extra oral Complaints & 134 & 64.1 \\
\hline Total & 209 & $100.0^{*}$ \\
\hline
\end{tabular}

* Approximately

The patient's perceived oral health status was exaggerated compared to actual oral hygiene status. This may be a way to attract empathy from health care workers, a demonstration of low level of psychosociological coping tendency living with the HIV/AIDS (26). Also, it can point out areas where self-awareness of dental problems is especially lacking and lastly, low self-esteem which has been associated with HIV/AIDS might play a role in their perceived oral health status (26). Hence, self-reported oral health status may not be reliable as an indicator of normative oral health status among the studied group. The disagreement between objective (normative) and subjective (perceived) needs point out areas where self awareness of dental problems are grossly lacking among the patients which would obviously guide their dental/health behaviour. The agreement between these two may mean that the patients are dentally aware of their problems. The objective needs assessment may not provide information on the impact of the disease on the quality of life of an individual. Ethically, health care decisions are now required to be more publicly agreed through a degree of consensus. 
The sum total of these results is that though a significant relationship exists between the perceived oral health status and the predictor variables, none of them could be relied upon to predict perceived oral health status. This can further be confirmed by the combined weight of the predictor variables, which was $7.8 \%$ of all the possible variables that could predict the perceived oral health status. So, there is likelihood that there are other variables which possibly are beyond the examined variables or the scope of the study.
The diversity of presenting complaints among PLWHA indicates that there are many symptoms associated with HIV/AIDS. The relevance of this to the oral health worker is that most of the presenting complaints may be from the oral cavity. Successful management of oral HIV lesions will facilitate the intake of adequate food, drinks and other nutritive materials which in turn may prevent weight loss, dehydration and poor general health, which are very commonly seen among PLWHA. Furthermore, the recognition and prompt diagnosis of oral HIV lesions is an imperative part of care for PLWHA.

Table 6: Periodontal objective (normative) needs of PLWHAs

\begin{tabular}{|c|c|c|c|}
\hline Lesions & Treatment needs & $\mathrm{n}$ & $\%$ \\
\hline No lesion & Nil & 11 & 5.3 \\
\hline Poor oral hygiene* & Scaling and polishing and $\mathrm{OHI}$ & 162 & 77.5 \\
\hline LGE & Home care and Scaling and polishing ${ }^{\mathrm{a}, \mathrm{b}}$ & 21 & 10.0 \\
\hline HIV-Gingivitis & $\begin{array}{l}\text { Debridement of slough and necrotic hard/soft tissue }+ \\
\text { Frequent irrigation with Povidone Iodine. Systemic } \\
\text { metronidazole and Chlorhexidine mouthwash }{ }^{\text {a,b }} \text {. }\end{array}$ & 6 & 2.9 \\
\hline HIV-Periodontitis & $\begin{array}{l}\text { Debridement of slough and necrotic hard/soft tissue }+ \\
\text { Frequent irrigation with Povidone Iodine. Systemic } \\
\text { metronidazole and Chlorhexidine mouthwash }{ }^{\text {a,b }} \text {. }\end{array}$ & 9 & 4.3 \\
\hline $\begin{array}{l}\text { Necrotising } \\
\text { stomatitis }\end{array}$ & $\begin{array}{l}\text { Debridement of slough and necrotic hard/soft tissue }+ \\
\text { Frequent irrigation with Povidone Iodine. Systemic } \\
\text { metronidazole and Chlorhexidine mouthwash }{ }^{\text {a, b }} \text {. }\end{array}$ & 00 & 00 \\
\hline Total & & 209 & 100.0 \\
\hline
\end{tabular}

a-Robinson (15); b-Robinson et al., (16)

*Poor oral hygiene without HIV-periodontal condition. Professional prophylaxis was done to prevent oral infection in an immune compromised patient.

Restorative treatment needs was mainly for amalgam fillings, this was similar to a previous reports $(27$, 28). This may result from xerostomia associated with HIV/AIDS (29). This was followed by partial dentures needs arising from previous extractions. It may be difficult to conclude that the observed caries level was due to HIV/AIDS. None required root canal treatment or complete dentures, while one required an obturator for a previous maxillectomy. Four needed full veneer crowns.

Scaling and polishing with oral hygiene instruction (OHI) was the most common need of the PLWHA examined. Scaling and complex periodontal therapy (such as root planning, open curettage, periodontal surgery etc) was only needed by a few. It has been reported that the prevalence of periodontal problem among adult Nigerians was high (30). This made it difficult to determine whether the periodontal needs were as a result of neglect of previous periodontal problems before the HIV infection or not. Patients should be encouraged to seek dental care so that periodontal problems do not progress to more severe periodontal conditions such as nectrotising stomatitis and cancrum oris. Meticulous attention to oral

hygiene and regular professional prophylaxis are essential to maintenance of periodontal health.

Few required oral surgical procedures. Two needed sequestrectomy and one for management of dentoalveolar abscess, indicating that the surgical needs of PLWHA may be less invasive and not complex. This was contrary to the two-third in need of dental extractions reported by Patton et al. (13).

More than half of the participants were at stage III of the disease indicating that many do not seek dental care early in the disease process (16). Stigmatisation may be associated with this late presentation and may account for the fewer patients seen in stage I. In addition, fewer patients in stage IV were seen and this may be as result of severe illness and death as the disease becomes terminal.

The limitation of this study is; the participants were those PLWHA who sought treatment in the health 
facilities in the study location, thus the experiences of those interviewed may not be generalised.

\section{Conclusion and recommendations}

The oral health status of the examined PLWHAs was poor. Good oral hygiene did not preclude the presence of severe periodontal diseases such as AUG. The normative and the perceived oral health evaluation were not in agreement in this study. The normative oral health care needs of PLWHAs are not complex and hence may be met at the district oral health care centres.

\section{References:}

1 UNAIDS/WHO. Global Summary of the HIV/AIDS Epidemic, December 1999: Joint United Nations programme on AIDS. Epidemiology fact sheet 2002. http://www.unaids.org (accessed 12/04/2007)

2 Weinert M, Grimes RM, Lynch DP. Oral manifestations of HIV diseases. Annals of Int. Med. 1996, 125: 485-96.

3 Silverman S, Miglioratti CA, Lozada-Nur F, Greenspan D, Conant MA. Oral findings in a people with or at risk for AIDS: a study of 375 homosexual males. J Am Dent Assoc. 1986, 112: 189-92.

4 Shiboski $\mathrm{CH}$, Palacio $\mathrm{H}$, Neuhaus JM Greenblatt RM. Dental care access and use among HIV-infected women. Amer J Public Health.1999, 89: 818-9.

5 Greene VA, Chu SY, Diaz T, Schable B. Oral health problems and use of dental services among HIV-infected adults. J Amer Assoc1997, 126: 1417-22.

6 Schulten ENM, ten Kate RW, Van der waal I. The impact of oral examination on the centres for Disease Control classification of subjects with HIV infection. Arch Intern Med 1991, 5: 355-64.

7 Tukutuku K, Muyembe TL, Kayembe K, Matuemba T, Sangua N, Sekele I. Prevalence of dental caries and gingivitis, and oral hygiene status among AIDS patients hospitalised in Kinshasa, Zaire. J oral Pathol Med 1990, 19: 271-2.

8. Mayanja B, Morgan D, Ross A, Whithworth J. The burden of muco-cutaneous conditions and the association with HIV-1 infection in a rural community in Uganda. Trop Med and Int Health 1999, 4: 349-54.

9. Brunswick A F, Nikias M. Dentist's Ratings and Adolescents' Perceptions of Oral Health. $J$ Dent Res 1975, 54: 836-43.

10. David J, Åstrøm A N, Wang N J. Prevalence and correlates of self-reported state of teeth among schoolchildren in Kerala, India. BMC Oral Health. 2006; 6: 10.
11. Segurado AC, Miranda SD, Latorre MD. Brazilian Enhancing Care Initiative Team. Evaluation of the care of women living with HIV/AIDS in Sao Paulo, Brazil. AIDS Patient Care STDS. 2003, 17:85-93.

12. Pinheiro A, Marcenes W, Zakrzewska JM, Robinson PG. Dental and oral lesions in HIV infected patients: a study in Brazil. Int Dent J. 2004, 54:131-7.

13. Patton LL, Strauss RP, McKaig RG, Porter DR, Eron JJ Jr. Perceived oral health status, unmet needs, and barriers to dental care among HIV/AIDS patients in a North Carolina cohort: impacts of race. J Public Health Dent. 2003, 63: 86-91.

14. Glick M, Burris S. The professional responsibility for care. Oral Dis. 1997; 3: S221-4.

15. Greene JC, Vermillion JR. Oral hygiene index: a method for classifying oral hygiene status. $\mathrm{J}$ Am. Dental Assoc 1964; 61: 172

16. EC-Clearinghouse on oral problems related to HIV-infection and WHO collaborating centre on oral manifestations of the Immunodeficiency virus Classification and diagnostic criteria for oral lesions in HIVinfection. J Oral Pathol Med 1993, 19:232-34

17. Robinson PG. The significance and management of periodontal lesions in HIV infection. Oral Dis. 2002, 8: (Suppl.2), 91-7.

18. Robinson PG, Adegboye A, Rowland RW, Yeung S, Johnson NW. Periodontal diseases and HIV infection. Oral Dis. 2002; 8: (Suppl.2), 144-50.

19. Statistical Package for Social Sciences Inc. SPSS for windows. Release 10.0, standard version. Chicago 1999: SPSS Inc.

20. Dean AG, Dean JA. EPI Info. Version 2000: A word processing, database and statistics program for public health on IBM-compatible microcomputer. Centres for Disease Control and Prevention, Atlanta: USA

21. Fleishman JA, Hsia DC, Hellinger FJ. Correlates of medical service utilisation among people with HIV infection. Health Serv Res 1994, 29: 527-48.

22. Odusanya SA. Tooth loss among Nigerians: causes and pattern of morbidity. Int. J Oramaxillofac Surg 1987, 16: 184-89.

23. Aderinokun GA. Characteristics of children attending the dental clinic (UCH) Ibadan. An indication of community awareness and attitude to oral health. Niger Dent J 1990, 2832.

24. Wanzala P, Manji F, Pindborg JJ, Plummer F. Low prevalence of oral mucosal lesions in HIV-1 seropositive African women. J Oral Pathol Med 1989, 18: 416-8. 
25. Arendorf T, Bredekamp B, Wood R, Okefe E. Oral manifestations of HIV infection in 600 Southern African patients. J Oral Pathol Med 1998, 27: 176-9

26. Mak WW, Cheung R Y M, Law R W, Woo J, Li P C K, Chung R WY, Examining attribution model of self-stigma on social support and psychological well-being among people with HIV+/AIDS. Social Science \& Medicine 2007; (in press).

27. Goddard G, Brown C, Ahmad AS. Oral disease prevalence among HIV-positive American
Indians in an urban clinic. J Psychoactive Drugs 2005, 37: 313-9.

28. Shubi F, Kahabuka FK, Fabian F, Nguvumali H. Caries status and opinions of people living with HIV/AIDS on oral health care providers' desired behaviour. Tanz Dent J 2006, 13: 5662.

29. Lin Al, Johnson DA, Stephan KT, Yeh CK. Alteration in salivary function in early HIV infection. J Dent Res 2003, 82: 719-24

30. Sheiham A, Jeboda SO. Periodontal disease in Nigeria: the problem and possible solutions. Odontostomatol Trop 1981, 4: 211-9 